Umiyati · D. Kurniadie

\title{
Pergesaran populasi gulma pada olah tanah dan pengendalian gulma yang berbeda pada tanaman kedelai
}

\section{Shifting of weeds population on soil tillage and the kinds of weed control in soybean plant}

Diterima : 15 November 2016/Disetujui : 15 Desember 2016 / Dipublikasikan : 30 Desember 2016

CDepartment of Crop Science, Padjadjaran University

\begin{abstract}
The research purpose is to know the shifting of weeds population in soil tillage and the kinds of weed control. The experiment was conducted from June to August 2016 in UPTD Seed Crops Development Center (BPBD) in Barepan Village sub district agricultural research Plumbon Cirebon district. The design used was a randomized block design with six treatment combinations were repeated 4 times. Such treatment is $\mathrm{A}=$ no tillage and weed control with herbicides, $\mathrm{B}=$ no tillage and weed control mechanic, $\mathrm{C}=$ no tillage and without weed control, $\mathrm{D}=$ maximum tillage and weed control with herbicides, $\mathrm{E}=$ maximum tillage and mechanic weed control and $\mathrm{F}=$ maximum tillage and without weed control. The results showed that there was type of weeds found 9 before treatment, which is dominated by weed Ludwegia octovalvis with SDR of $19.02 \%$, weed codominan consists of Fimbristylis miliace SDR $15.55 \%$, Echinocloa crusgali with SDR $13.42 \%$, Monochoria vaginalis with SDR 12.39 \%, Cyperus iria SDR $10.03 \%$. After treatments of weeds which always appears on each treatment consists of 3 species, namely Echinocloa colona $l$. Cyperus iria l., Cynodon dactylon Althernanthera piliodes $L$. The dominance of weed Ludwegia perennis $\mathrm{L}$ after treatment was replaced by the activities of the control and the processing of land. As a result of the use of the herbicide continuously in one area, there will be changes in weed dominance of weed community sensitive become tolerant weeds. Echinocloa weeds and Cyperus iria L colona found in all experimental plots, this is because both the weed seeds and reproduce them with stolon.
\end{abstract}

Keywords: Weed shifting · Weed control · Soil tillage

\footnotetext{
Dikomunikasikan oleh Yudithia Maxiselly

Umiyati · D. Kurniadie

Departemen Agroteknologi, Fakultas Pertanian,

Uiversitas Padjadjaran.

Raya Bandung-Sumedang km. 21 Jatinangor-Jawa Barat

Korespondensi: umiyati_uum@yahoo.com
}

Sari Tujuan dari perobaan ini adalah mengetahui pergeseran populasi gulma pada olah tanah dan pengendalian gulma yang berbeda. Percobaan dilakukan dari bulan Juni - Agustus 2016 di UPTD Balai Pengembangan Benih Palawija (BPBP) Desa Barepan Kab. Cirebon. Rancangan yang diguna-kan adalah Rancangan Acak dengan 6 kombinasi perlakuan yang diulang sebanyak 4 kali. Perlakuan tersebut adalah: $\mathrm{A}=$ Tanpa olah tanah dan pengendalian gulma dengan herbisida, $\mathrm{B}=$ Tanpa olah tanah dan pengendalian gulma secara mekanis, $C=$ Tanpa olah tanah dan tanpa pengendalian gulma, $\mathrm{D}$ = Olah tanah sempurna dan pengen-dalian gulma dengan herbisida, $\mathrm{E}=$ Olah tanah sempurna dan pengendalian gulma secara meka-nis dan $\mathrm{F}=$ Olah tanah sempurna dan tanpa pengendalian gulma. Hasil Penelitian menun-jukkan bahwa ditemukan 9 jenis gulma sebelum perlakuan, yang didominasi oleh gulma Ludwegia octooalvis dengan SDR sebesar 19,02 \%, gulma codominan terdiri dari Fimbristylis miliace SDR 15,55 \%, Echinocloa crusgali dengan SDR $13,42 \%$, Monochoria vaginalis dengan SDR 12,39\%, Cyperus iria SDR 10,03 \%. Setelah perlakuan gulma yang selalu muncul pada setiap perlakuan terdiri dari 3 spesies, yaitu Echinocloa colona L. Cyperus iria L, Cynodon dactylon $\mathrm{L}$ dan Althernanthera piliodes $\mathrm{L}$. Dominasi gulma Ludwegia perennis $L$ setelah perlakuan digantikan oleh adanya kegiatan pengendalian dan pengolahan tanah. Perubahan spektrum gulma cukup besar kemungkinannya disebabkan oleh adanya tekanan selektivitas yang cukup tinggi dari herbisida yang digunakan. Akibat penggunaan satu jenis herbisida secara terus menerus pada satu lahan, maka akan terjadi perubahan dominasi gulma dari komunitas gulma yang peka menjadi gulma yang toleran. Gulma Echinocloa colona L dan Cyperus iria ditemui di seluruh petak percobaan, hal ini karena keduanya memperbanyak diri dengan biji dan stolon.

Kata kunci : Pergeseran gulma - Olah tanah . Pengendalian gulma 


\section{Pendahuluan}

Gulma pada tanaman kedelai menyebabkan terjadinya persaingan dalam pengembilan unsur hara, air, cahaya dan ruang tumbuh. Penurunan hasil akibat persaingan dengan gulma dapat mencapai 52,49 persen (Hasanudin cit, Husnalita et al., 1996). Menurut Arjasa dan Bangun (1985) bila gulma yang tumbuh pada tanaman kedelai tidak disiang penurunan hasil berkisar antara 18 - 76 persen. Oleh karena itu agar tanaman dapat memberikan hasil yang tinggi maka tanaman harus mampu mendapatkan faktor tumbuh yang optimal dengan meminimalkan terjadinya persaingan inter maupun intra spesifik. Hal ini dapat dilakukan dengan pengaturan jarak tanam dan dengan pengendalian gulma.

Pengelolaan gulma pada saat pembukaan lahan biasanya dilakukan dengan cara pengolahan tanah. Tetapi pengolahan tanah memerlukan tenaga kerja yang banyak dan waktu yang lama Olah Tanah Sempurna (OTS) dapat memberikan peluang bagi biji gulma yang dorman untuk berkecambah akibat pembalikan tanah kemudian tumbuh dan berkembang mengikuti pertumbuhan tanaman sehingga dapat mempengaruhi produktivitas tanaman. Untuk mengatasi dampak negatif tersebut maka diperlukan cara persiapan lahan siap tanam lainnya seperti Sistem Tanpa Olah Tanah (TOT) yang merupakan salah satu alternatif dalam penyiapan lahan untuk tanaman kedelai. Dengan penerapan budidaya TOT, maka sisa tanaman dan gulma yang ada dikendalikan dengan pengendalian mekanis atau dengan menyemprotkan herbisida. sistem produksi pertanian modern, pengendalian gulma merupakan upaya untuk menekan pertumbuhan gulma hingga tidak menimbulkan gangguan terhadap tanaman.

Pertumbuhan gulma dan luas penyebarannya di suatu daerah sangat dipengaruhi oleh keadaan lingkungan tempat gulma tersebut tumbuh, praktek-praktek bercocok tanam, dan juga jenis tanaman pangan yang ada.Faktorfaktor lingkungan seperti jenis dan tingkat kesuburan tanah, ketinggian tempat, keadaan air tanah, dan habitat (tempat tinggal makhluk hidup) yang berperan dalam membatasi pertumbuhan dan penryebaran gulma. Penyebaran gulma dapat terjadi dengan cepat dari satu tempat ke tempat lainnya. Perantara penyebaran gulma dilakukan dengan bantuan angin, air, binatang, manusia, dan mekanisme ledakan.
Hampir semua cara bercocok tanam akan sangat tergantung pada cara-cara pengendalian gulma baik cara manual, mekanis maupun kimia. Masing-masing cara pengendalian mem-punyai kemampuan untuk menurunkan tingkat kepadatan gulma secara maksimal. Cara pengendalian gulma mekanis merupakan cara pengendalian gulma yang tidak selektif. Tetapi ada beberapa cara pengolahan tanah seperti olah tanah sempurna (OTS), dan tanpa olah tanah (TOT) dapat mengendalikan gulma secara selektif dan dapat mempengaruhi komposisi jenis gulma. Hasil dari cara pengolahan tanah ini kepadatan gulma dan komposisi jenisnya akan menjadi berkurang kemudian akan terjadi perubahan populasi yang mengarah ke satu jenis komunitas pertanian yang terdiri dari tanaman budidaya dan jenis-jenis gulma yang tumbuh disekitar larikan dengan jumlahnya sedikit (Rao, 2000). Perubahan komposisi jenis gulma akan selalu terjadi pada setiap pengen-dalian gulma yang dilakukan, perubahan akan lebih tampak secara nyata jika dilakukan dengan menggunakan herbisida. Berkaitan dengan hal tersebut di atas, maka perlu diuji cara pengo-lahan lahan dan pengendalian gulma yang berbeda dapat menyebabkan pergeseran gulma yang ada pada tanaman kedelai.

\section{Bahan dan Metode}

Penelitian dilaksanakan di UPTD Balai Pengembangan Benih Palawija (BPBP) Plumbon Desa Barepan Kabupaten Cirebon. Metode penelitian yang digunakan adalah metode eksperimen dengan Rancangan Acak Kelompok (RAK). Percobaan ini terdiri dari 6 kombinasi perlakuan pengendalian gulma dan pengolahan tanah yang masing-masing diulang 4 kali, sehingga akan terdapat 24 petak percobaan. Perlakuan tersebut adalah A = Tanpa Olah Tanah dan pengendalian gulma dengan herbisida, $\mathrm{B}=$ Tanpa Olah Tanah dan pengendalian gulma secara mekanis, $\mathrm{C}=$ Tanpa Olah Tanah dan tanpa pengendalian gulma, $\mathrm{D}=$ Olah Tanah Sempurna dan pengendalian gulma dengan herbisida, $\mathrm{E}=$ Olah Tanah Sempurna dan pengendalian gulma secara mekanis dan F= Olah Tanah Sempurna dan tanpa pengendalian gulma. Pengamatan terhadap gulma meliputi jenis gulma, dominasi gulma (SDR) dan koefisien komunitas gulma (C). Dominansi jenis gulma dihitung dengan menggunakan Summed Dominance Ratio (SDR) setiap jenis gulma yang ditetapkan dari contoh yang diambil dengan 
ukuran kuadrat, terdapat 5 petak contoh berukuran $0,5 \times 0,5 \mathrm{~m}$ pada setiap petak percobaan. Summed Dominance Ratio dihitung berdasarkan rumus:

$$
\mathrm{SDR}=\frac{\text { Nilai penting }}{3} \times 100 \%
$$

Nilai penting $=$ Kerapatan nisbi + Frekuensi nisbi + Dominansi nisbi.

Koefisien Komunitas (C) dihitung dengan menggunakan rumus berikut:

$$
\mathrm{C}=\frac{2 \mathrm{~W}}{\mathrm{a}+\mathrm{b}} \times 100 \%
$$

Dimana : $\mathrm{C}=$ Koefisien komunitas; $\mathrm{W}=$ Jumlah dari dua kuantitas terendah untuk jenis dari masing-masing Komunitas; $a=$ Jumlah dari seluruh kuantitas pada komunitas pertama; $b=$ Jumlah dari seluruh kuantitas pada komunitas kedua

\section{Hasil dan Pembahasan}

Hasil analisis vegetasi gulma di lokasi pengujian sebelum diberi perlakuan ditemukan terdapat 9 species gulma (Tabel 1), dimana gulma yang mendominasi lahan tersebut adalah Ludwegia octovalvis dengan SDR sebesar 19,02\%, gulma co dominan terdiri dari Fimbristylis miliace SDR 15,55 \%, Echinocloa crusgali dengan SDR 13,42 \%, Monochoria vaginalis dengan SDR 12,39 \%, Cyperus iria SDR 10,03\%.

Komposisi dan Jenis Gulma Setelah Perlakuan. Tabel 2 nampak bahwa secara keseluruhan ada 9 spesies gulma yang muncul pada seluruh lahan. Dari 9 spesies tersebut, yang selalu muncul pada setiap perlakuan ada 3 spesies, yaitu Echinocloa colona L. Cyperus iria L, Cynodon dactylon L dan Althernanthera piliodes L. Gulma yang muncul pada 3 MST, bila dilihat dari golongannya adalah golongan rumputan (3 spesies), dan gulma daun lebar (1 species). Pada 3 MST, perlakuan penyiangan sudah dilakukan, sehingga perbedaan gulma dikarenakan perbedaan pengendalian dan pengolahan lahan.

Tabel 1. Hasil Analisis Vegetasi Gulma Sebelum Perlakuan.

\begin{tabular}{lr}
\hline \hline Nama Spesies & SDR \\
\hline Echinocloa colona & 13,42 \\
Fimbristylis milicea & 15,55 \\
Ludwegia perrennis & 19,02 \\
Commelina diffusa & 7,87 \\
Cynodon dactylon & 8,64 \\
Monochoria vaginalis & 12,39 \\
Althernanthera piliodes & 8,87 \\
Cyperus iria & 10,03 \\
Leptochloa sinencis & 4,21 \\
\hline \multicolumn{1}{c}{ Jumlah } & 100,00 \\
\hline \hline
\end{tabular}

Dominasi gulma Ludwegia perennis $L$ setelah perlakuan digantikan oleh adanya kegiatan pengendalian dan pengolahan tanah. Pendapat ini diperkuat dengan yang dikemukakan oleh Rao (2000), bahwa Perubahan komposisi jenis gulma akan selalu terjadi pada setiap pengendalian gulma yang dilakukan, perubahan akan lebih tampak secara nyata jika dilakukan dengan menggunakan herbisida. Perubahan spektrum gulma cukup besar kemungkinannya disebabkan oleh adanya tekanan selektivitas yang cukup tinggi dari herbisida yang digunakan. Akibat penggunakan satu jenis herbisida secara terus menerus pada satu lahan, maka akan terjadi perubahan dominasi gulma dari komunitas gulma yang peka menjadi gulma yang toleran. Gulma Echinocloa colona L dan Cyperus iria ditemui pada seluruh petak percobaan, hal ini karena kedua gulma tersebut memperbanyak diri dengan biji dan stolon.

Tabel 2. Nilai SDR (\%) Masing-masing Species Gulma Umur 3 Minggu Setelah Tanam (MST) Kedelai.

\begin{tabular}{lccccccr}
\hline \hline \multirow{2}{*}{ Nama Species Gulam } & \multirow{2}{*}{ Sebelum } & \multicolumn{7}{c}{ Pengamatan 3 MSA } \\
\cline { 3 - 8 } & & A & B & C & D & E & F \\
\hline Echinocloa colona & 13,42 & 9,12 & 25,5 & 26,25 & 2,95 & 31,45 & 46,55 \\
Fimbristylis milicea & 15,55 & 8,04 & 0 & 21,24 & 0 & 22,65 & 26,13 \\
Ludwegia perennis & 19,02 & 6,67 & 10,75 & 12,50 & 0 & 1,89 & 2,65 \\
Cyperus iria & 7,87 & 31,25 & 19,52 & 12,26 & 19,35 & 15,58 & 12,65 \\
Cynodon dactylon & 8,64 & 11,28 & 0,5 & 13,1 & 25,18 & 20,25 & 9,25 \\
Monochoria vaginalis & 12,39 & 4,07 & 18,21 & 3,17 & 0 & 0,25 & 0,25 \\
Althernanthera piliodes & 8,87 & 11,19 & 2,43 & 3,25 & 32,57 & 1,76 & 2,58 \\
Commelina diffusa & 10,03 & 25,48 & 0 & 4 & 20,25 & 0,75 & 0 \\
Leptochloa sinencis & 4,21 & 2,67 & 23,17 & 17,09 & 0 & 5,75 & 0 \\
\hline \hline
\end{tabular}

Keterangan Perlakuan : A = TOT + Herbisida, B = TOT + Mekanis, $\mathrm{C}=\mathrm{TOT}+$ Tanpa pengendalian, $\mathrm{D}=$ OTS + Herbisida, E = OTS + Mekanis, F = OTS + Tanpa pengendalian. 
Tabel 3 . Koefisien Komunitas Gulma (C) Umur 3 MSA.

\begin{tabular}{cc}
\hline \hline $\begin{array}{c}\text { Perlakuan yang } \\
\text { Dibandingkan }\end{array}$ & $\begin{array}{c}\text { Koefisien Komunitas } \\
\text { Gulma }(\mathrm{C} \%)\end{array}$ \\
\hline A : B & 42,55 \\
A : C & 60,27 \\
A : D & 36,47 \\
A : E & 51,34 \\
A : F & 44,54 \\
B : C & 71,7 \\
B : D & 62,18 \\
B : E & 51,23 \\
B : F & 43,98 \\
C : D & 35,56 \\
C : E & 83,25 \\
C : F & 74,48 \\
D : E & 35,56 \\
D : F & 27,43 \\
E : F & 79,65 \\
\hline \hline
\end{tabular}

Keterangan : A = TOT + Herbisida, B = TOT + Mekanis, $\mathrm{C}=\mathrm{TOT}+$ Tanpa pengendalian, $\mathrm{D}=$ OTS + Herbisida, E = OTS + Mekanis, F = OTS + Tanpa pengendalian

Tabel 3 menunjukkan bahwa pada umur 3 MSA, antar perlakuan pengendalian mekanis dan pengendalian herbisida mempunyai nilai $\mathrm{C}<75 \%$ yang berarti bahwa komunitas gulma dua perlakuan tersebut tidak sama. Perlakuan pengendalian dan tanpa pengendalian mem-punyai nilai $\mathrm{C}$ $(60,27 \%)$ tetapi masih dibawah $75 \%$ berarti komunitas gulma dua perlakuan tersebut beragam. Perlakuan pengolahan tanah (TOT) dan pengolahan tanah sempurna (OTS) mempunyai nilai C > $75 \%$ yang berarti komunitas gulma dua perlakuan tersebut seragam.

Hasil dari cara pengolahan tanah ini kepadatan gulma dan komposisi jenisnya akan menjadi berkurang kemudian akan terjadi perubahan populasi yang mengarah ke satu jenis komunitas pertanian yang terdiri dari tanaman budidaya dan jenis-jenis gulma yang tumbuh disekitar larikan dengan jumlahnya sedikit (Rao, 2000)

Perubahan komposisi jenis gulma akan selalu terjadi pada setiap pengendalian gulma yang dilakukan, perubahan akan lebih tampak secara nyata jika dilakukan dengan menggunakan herbisida. Perubahan spektrum gulma cukup besar kemungkinannya disebabkan oleh adanya tekanan selektivitas yang cukup tinggi dari herbisida yang digunakan. Akibat penggunaan herbisida satu jenis secara terus menerus pada satu lahan, maka akan terjadi perubahan dominasi gulma dari kominas gulma yang peka menjadi gulma, disebabkan oleh adanya tekanan selektivitas yang cukup tinggi dari herbisida yang digunakan. Akibat peng-gunaan herbisida satu jenis secara terus menerus pada satu lahan, maka akan terjadi perubahan dominasi gulma dari kominas gulma yang peka menjadi gulma yang toleran.

\section{Kesimpulan}

Gulma yang mendominasi lahan sebelum perlakuan diberikan adalah Ludwegia octovalvis dengan nilai SDR sebesar 19,02 \%. Dominasi gulma Ludwegia perennis $L$ setelah perlakuan digantikan oleh adanya kegiatan pengendalian dan pengolahan tanah. Dominasi gulma daun lebar seperti Ludwegia perennis $L$ digantikan oleh gulma Echinocloa colona L dan Cyperus iria ditemui pada seluruh petak percobaan, hal ini karena kedua gulma tersebut memperbanyak diri dengan biji dan stolon. perlakuan pengendalian mekanis dan pengendalian herbisida mempunyai nilai $\mathrm{C}<75$ \%yang berarti bahwa komunitas gulma dua perlakuan tersebut tidak sama. Perlakuan pengendalian dan tanpa pengendalian mempunyai nilai $\mathrm{C}$ $(60,27 \%)$ tetapi masih dibawah $75 \%$ berarti komunitas gulma dua perlakuan tersebut beragam. Perlakuan pengolahan tanah (TOT) dan pengolahan tanah sempurna (OTS) mempunyai nilai C > 75 \% yang berarti komunitas gulma dua perlakuan tersebut seragam.

\section{Daftar Pustaka}

Chaerudin dan R. Noor. 1996. Pengendalian Gulma pada penyiapan Lahan Budidaya Padi di Lahan Tadah Hujan Kalimantan Selatan. Prosiding Konferensi XIII HIGI. h 411- 414.

Koocheki, A., N. Mehdi, A. Leila, G. Reza. 2009. Effect of cropping systems and crop rotations on weeds. Agron. Sustain. Dev. 29:401-408.

Metusala, D. 2006. Studi Waktu Aplikasi dan Dosis Herbisida Campuran Atrazine dan Mesotrione pada Pengendalian Gulma terhadap Hasil dan Kualitas Hasil Jagung (Zea mays). Skripsi (tidak dipublikasikan). Yogyakarta: Universitas Pembangunan Nasional "Veteran" Yogyakarta, Fakultas Pertanian, Jurusan Agronomi. $100 \mathrm{hlm}$.

Rao, V.S. Principle of weed Science. 2000. Published by Science. Inc., NH.,USA. 